\title{
From a three-component synthesis to multistep cascade reactions. Twenty years in the chemistry of $N$-(1-haloalkyl)azinium halides
}

\author{
Jean Jacques Vanden Eynde* and Annie Mayence \\ Académie Universitaire Wallonie-Bruxelles, Université de Mons-Hainaut, \\ Laboratoire de Chimie Organique, 20 Place du Parc, B-7000 Mons, Belgique \\ E-mail:jjvde@umh.ac.be
}

Dedicated to Professor Ernst Anders on the occasion of his $65^{\text {th }}$ birthday

\begin{abstract}
$N$-(1-Haloalkyl)azinium halides are readily available through a three-component reaction of an azine, an aldehyde, and a thionyl halide. Those salts represent activated forms of the starting aldehydes and can be used advantageously for the preparation of other azinium salts, imines, 1,1diamines, and a wide range of nitrogen (fused) heterocycles. Recently it has also been demonstrated that $N$-(1-haloalkyl)azinium halides can be transformed into bis(1,3,4-thiadiazolo)1,3,5-triazinium halides, a novel class of versatile tricyclic systems that exhibits many useful synthetic potentialities.
\end{abstract}

Keywords: Synthesis, mechanistic studies, nitrogen heterocycles, multicomponent reactions

\section{Contents}

1. Introduction

2. Preparation of $N$-(1-haloalkyl)azinium halides

3. Reactivity of $N$-(1-haloalkyl)azinium halides

3.1. Substitution of the halogen atom

3.2. Substitution of the halogen atom and the heterocyclic moiety

3.3. Recent developments: preparation and reactivity of bis(1,3,4-thidiazolo)-1,3,5triazinium halides

4. Conclusions

5. References 


\section{Introduction}

The chemistry of $N$-(1-haloalkyl)heteroarylium salts (1, Figure 1), one of the leading activities of E. Anders and his group, was reviewed comprehensively in 2000 in the series "Advances in Heterocyclic Chemistry". ${ }^{1}$ The aim of the present paper is to summarize that review and to highlight recent developments in the field.

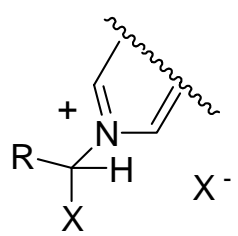

1
$\mathrm{X}=\mathrm{Cl}, \mathrm{Br}$

$\mathrm{R}=$ alkyl, aryl, heteroaryl

Figure 1. General structure of $N$-(1-haloalkyl)heteroarylium halides $\mathbf{1}$.

\section{Preparation of $N$-(1-haloalkyl)pyridinium Halides}

The first $N$-(1-haloalkyl)pyridinium halides (3, Scheme 1) described in the literature were obtained by bromination of phenacyl pyridinium derivatives 2 . The experiments were performed by Kroehnke in the 1930s. ${ }^{2}$ Since that time only a few scattered reports have mentioned such salts. Among them (see ref 1 for an exhaustive list), let us mention (Scheme 1) that (chloromethyl)pyridinium salts $\mathbf{4}$ and $\mathbf{5}$ have been prepared $^{3}$ from pyridine and chloroiodomethane or from 2-pyridyl platinium (II) complexes and dichloromethane. $\mathrm{N}$ (Trifluoromethyl)- and $N$-(difluoromethyl)-4-(dimethylamino)pyridinium bromides $(6,7)$ have been synthesized ${ }^{4}$ by a two-step sequence as illustrated in Scheme 1.

Two decades ago, ${ }^{5}$ Anders developed a procedure that has the advantage of a much wider scope of applicability. ${ }^{6}$ This three-component reaction involves an azine, an aldehyde, and a thionyl halide (Scheme 2) in an inert solvent, generally at room temperature and without any particular experimental precaution. Numerous nitrogen heterocycles have been used in those reactions, including pyridine, 3-bromopyridine, 3-methylpyridine, pyridine-3-carbonitrile, methyl pyridine3-carboxylate, 4-tert-butylpyridine, 4-(dimethylamino)pyridine, pyridine-4-carbonitrile, pyrimidine, pyrazine, quinoline, isoquinoline, and even 1-methylimidazole. Aromatic, heteroaromatic, or aliphatic aldehydes can be used in the presence of thionyl chloride or bromide indifferently. The highly branched trimethylacetaldehyde ${ }^{6 \mathrm{c}}$ and gaseous formaldehyde, ${ }^{6 \mathrm{~d}}$ generated from paraformaldehyde, have also been successfully employed. Yields are nearly quantitative. Most of the salts, although sometimes hygroscopic, are stable at room temperature for several years and soluble in many organic solvents. 
<smiles>[R]C(=O)C(Br)[n+]1ccc([R])cc1</smiles>

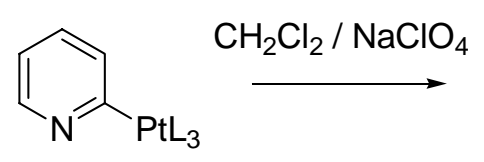<smiles>CC(Cl)[n+]1ccccc1C=CC=C(Cl)Cl</smiles>

$\mathrm{Br}^{-}$
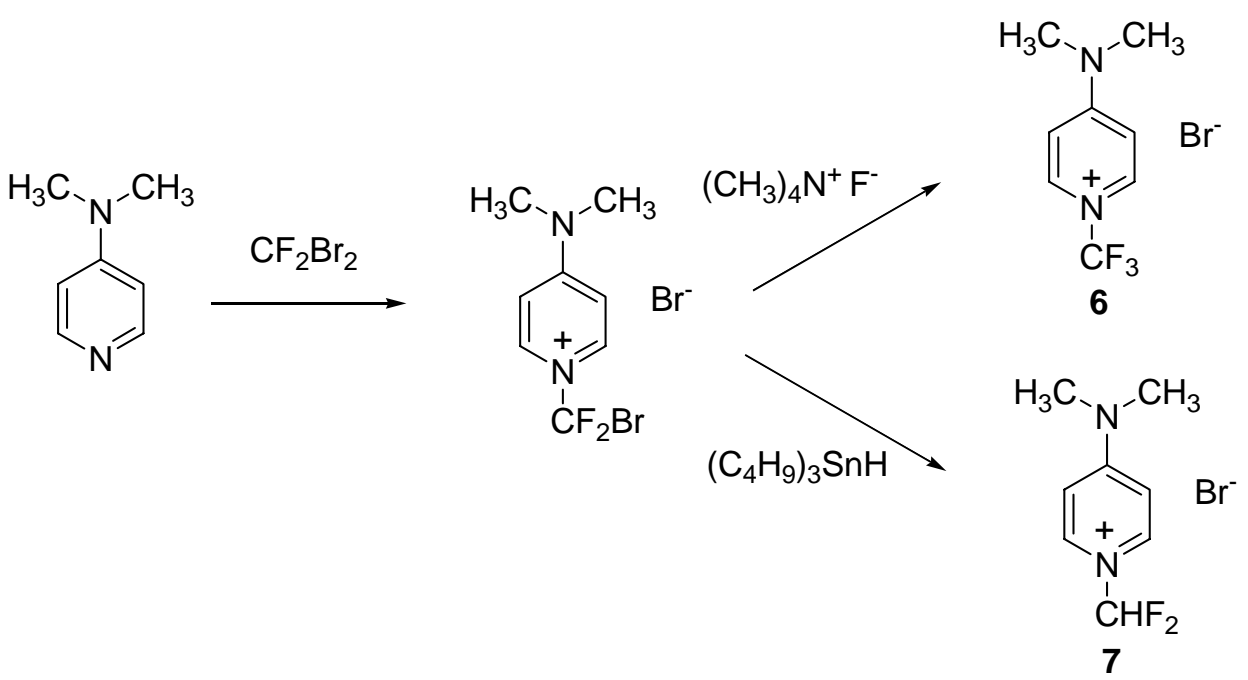

$\mathrm{R}^{\prime}=\mathrm{H}$, phenyl, methyl

Scheme 1<smiles>[R]C=[O+][C-]1[CH]C=NC1</smiles><smiles>[X]C([R])([X])N1CCCC1</smiles>

\section{Scheme 2}


More recently polymer-bound $N$-(1-chloroalkyl)quinolinium (8) and isoquinolinium (9) chlorides (Scheme 3) have been described. ${ }^{7}$ Based on exploratory experiments and a kinetic study ${ }^{6 c}$ of the rate of formation of $N$-(1-haloalkyl)azinium halides, Merrifield's resin linked through an ether bound to position 6 of quinoline or position 5 of isoquinoline emerged as highly attractive insoluble auxiliaries. Such solid reagents were readily available by coupling Merrifield's resin with 6-hydroxyquinoline or 5-hydroxyisoquinoline in a hot mixture of aqueous sodium hydroxide and $N, N$-dimethylformamide for 6 hours. Noteworthy reaction time could be decreased to five minutes when performing the experiment under microwave irradiation (Biotage Initiator ${ }^{\mathrm{TM}}$ ). Conversion of the aldehydes was effected at room temperature and the so-obtained polymer-bound salts could be kept for months without any degradation.
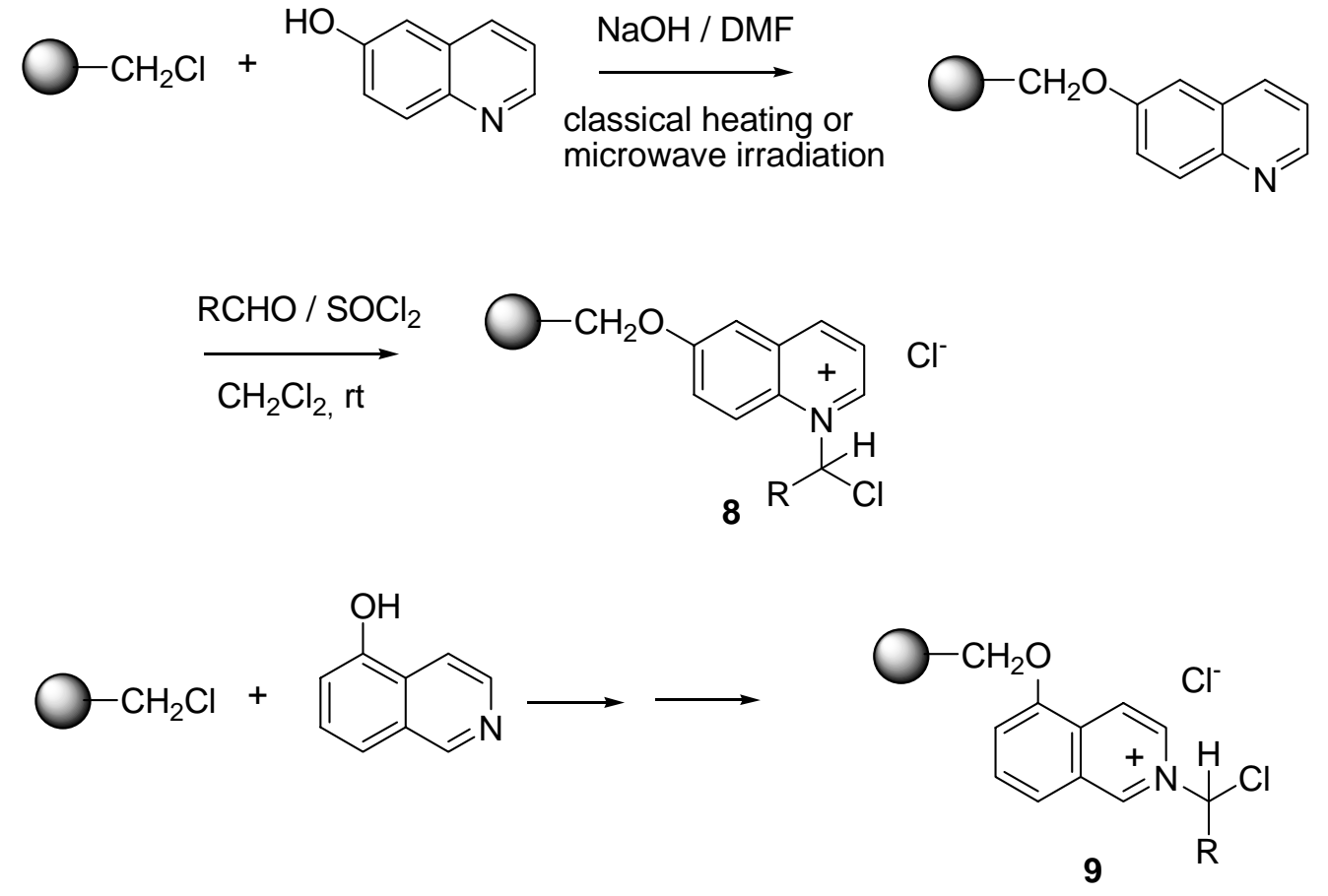

\section{Scheme 3}

The mechanism suggested (Scheme 4) to explain the formation of $\mathrm{N}$-(1haloalkyl)heteroarylium halides (1) by the three-component reaction discovered by Anders is based on a ${ }^{1} \mathrm{H}-\mathrm{NMR}$ study of the rates of formation of $\mathbf{1} .{ }^{6 \mathrm{c}}$ Kinetic data ruled out the presence of a preequilibrium between the aldehyde and the thionyl halide or between the heterocycle and the thionyl halide. It was therefore suggested ${ }^{6 c}$ that the azine could add to the aldehyde to form a betaine prior to interact with the thionyl halide. subsequent O-sulfinylation and elimination of sulfur dioxide would afford the salts. 


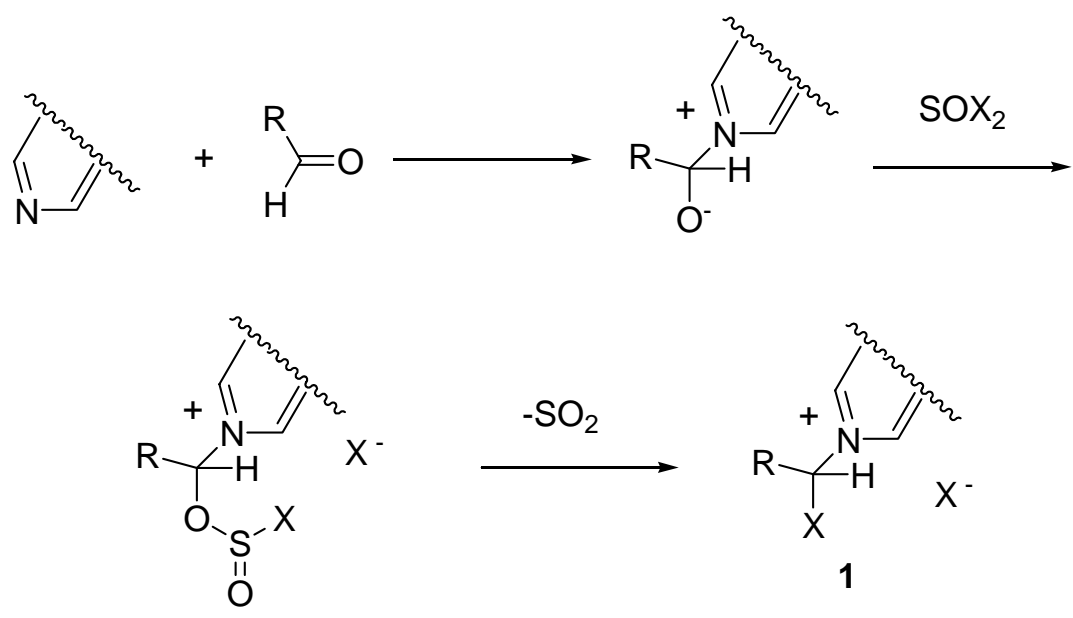

\section{Scheme 4}

\section{Reactivity of the salts}

In $N$-(1-haloalkyl)heteroarylium halides both the halogen atom and the heterocyclic moiety can be displaced by nucleophiles. Theoretical ${ }^{1}$ calculations and experimental ${ }^{6 \mathrm{~b}}$ data revealed that substitution of the halogen atom is the rate-determining step.

\subsection{Substitution of the halogen atom}

Monosubstitution of the halogen atom has been observed in the reaction between $\mathrm{N}$-[halo(4methylphenyl)methyl]pyridinium halides (10, 13, Scheme 5) and various ionic nucleophiles. ${ }^{5,6}, 8$ Derivatives 11 (37\%), 12 (46 \%), 14 (85\%), 15 (86 \%), and 16 (71\%) were obtained from potassium trithiocarbonate, sodium hydrogensulfite, sodium thiophenolate, potassium phthalimide, and cesium fluoride respectively.

As depicted in Scheme 6, monosubstitution of the halogen atom also occurred when $\mathrm{N}$-(1haloalkyl)azinium halides were treated with uncharged nucleophiles. ${ }^{5,6 b}$ The parent $N$ (chloromethyl)pyridinium chloride 17 (Scheme 6) reacted with 4-(dimethylamino)pyridine or 4picoline to afford the bisoniums 18 (90 \%) and 19 (77\%). ${ }^{6 d}$ In the presence of triphenylphosphine or 1-methylimidazole, the $N$-[halo(4-methylphenyl)methyl]pyridinium halides 10 and 13 yielded compounds 20 (91\%), 21 (95\%), and 22 (93\%). It is worth mentioning that, in agreement with $a b$ initio and semiempirical calculations, ${ }^{6 \mathrm{~d}, 9}$ the amino function of the 3- or 5-amino-1-methyl-1H-1,2,4-triazoles and that of 2-amino-5-methyl-1,3,4thiadiazole (Scheme 6) were not involved when those heterocycles were reacted with one equivalent of several $N$-(1-chloroalkyl)pyridinium chlorides (23, 30-95 \%). 

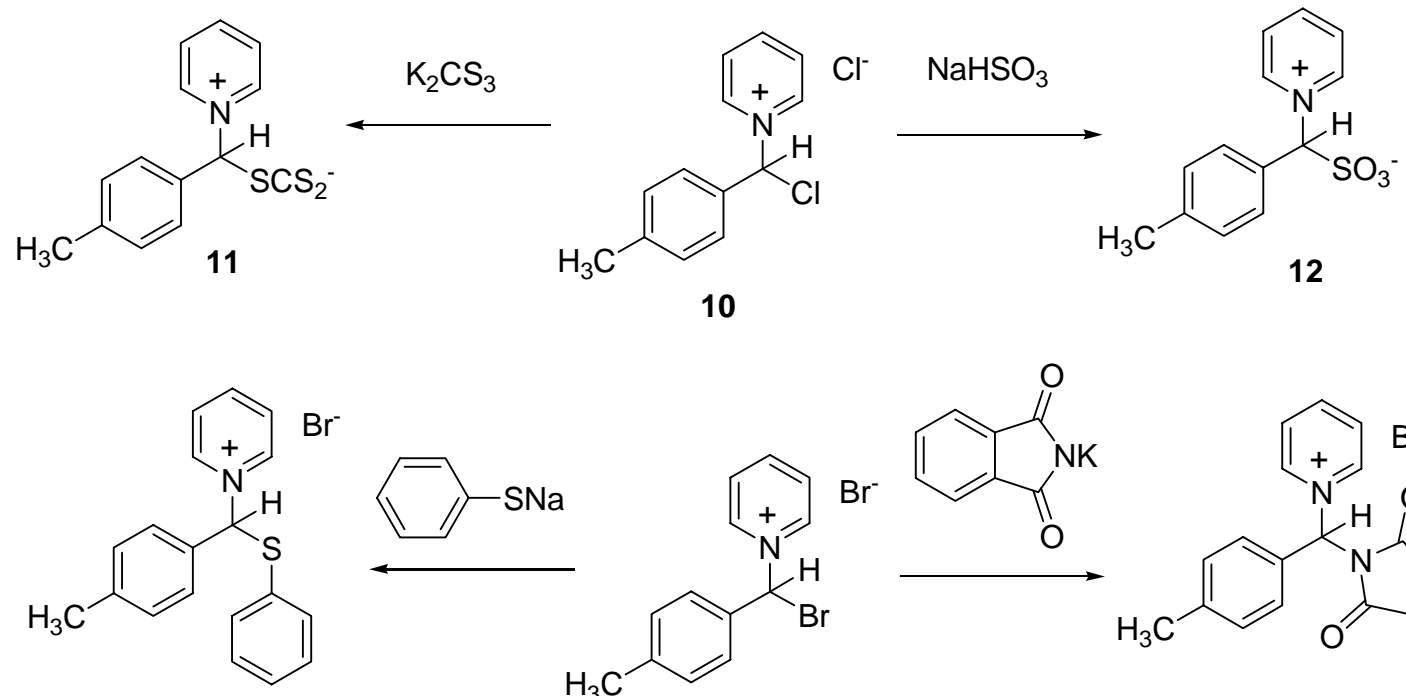

14

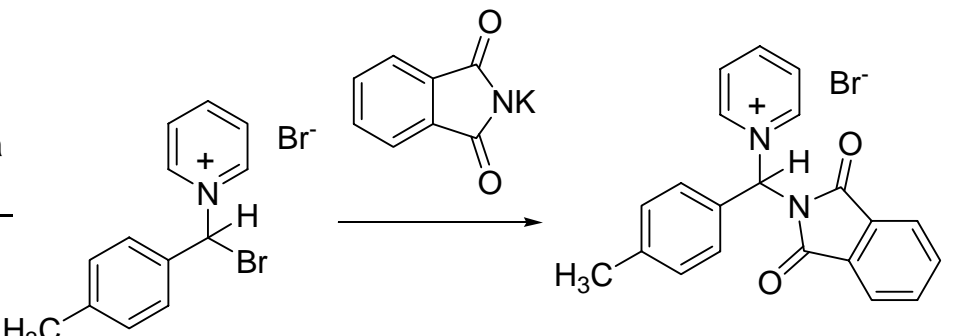

15

13

$\mathrm{CsF}_{2}$<smiles>Cc1ccc(C(F)(F)[n+]2ccccc2)cc1</smiles>

16

Scheme 5 


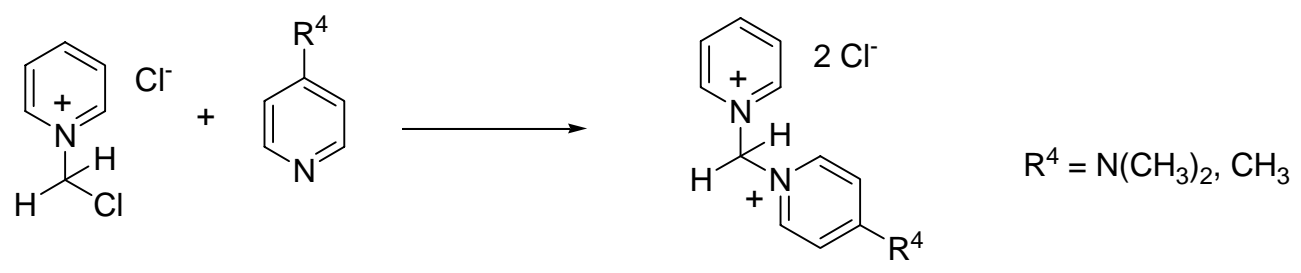

18, 19<smiles>[X]c1cccc[n+]1[C+]([PH3+])(c1ccccc1)c1ccc(C)cc1</smiles>

20,21

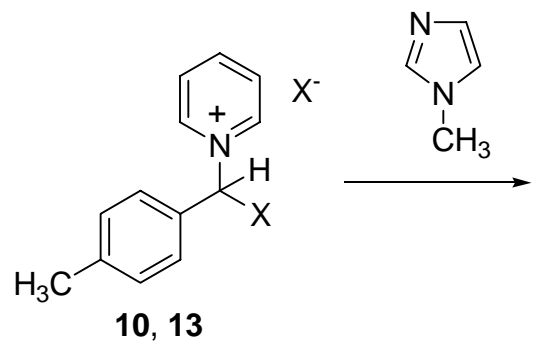

10, 20: $\mathrm{X}=\mathrm{Cl}$

13, 21: $\mathrm{X}=\mathrm{Br}$
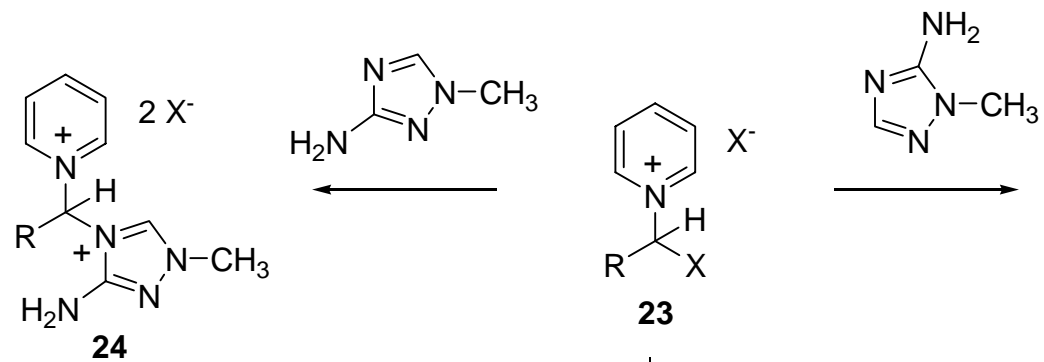

23<smiles>[R2]C(c1ccc(C)cc1)([n+]1ccccc1)[n+]1ccn(C)c1</smiles><smiles>[3H]c1nnc(C)s1</smiles>

$$
\mathrm{R}=\mathrm{H}, \text { alkyl, aryl }
$$

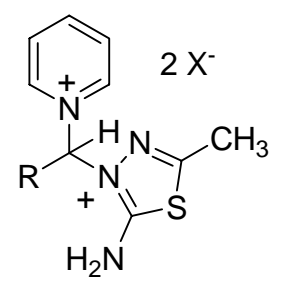

26

\section{Scheme 6}

$N$-(1,2,2,2-tetrachloroethyl)pyridinium chloride (27), prepared in $80 \%$ yield from trichloroacetaldehyde, pyridine, and thionyl chloride, gave rise to a particular result ${ }^{6 \mathrm{~d}}$ when 
treated with pyridine or 5-amino-1-methyl-1H-1,2,4-triazole because $N$ (trichloroethenyl)pyridinium chloride (28, $70 \%$ ) was isolated. The strong withdrawing effect exerted by the trichlorovinyl group enabled further nucleophilic reactions at the C(4)-position of the pyridinium moiety yielding 1,4-dihydropyridines. In that way, 4-phenylmethyl-, 4phosphonato-, and 4-[(di-2-propoxy)phosphoryl]-1-(trichloroethenyl)-1,4-dihydropyridines [29 (73\%), 30 (91\%), 31 (80 \%), Scheme 7] could be obtained. Surprisingly 27 reacted with triphenylphosphine to afford ${ }^{6 \mathrm{~d}} \mathrm{~N}$-(2,2-dichloroethenyl)pyridinium chloride (32).

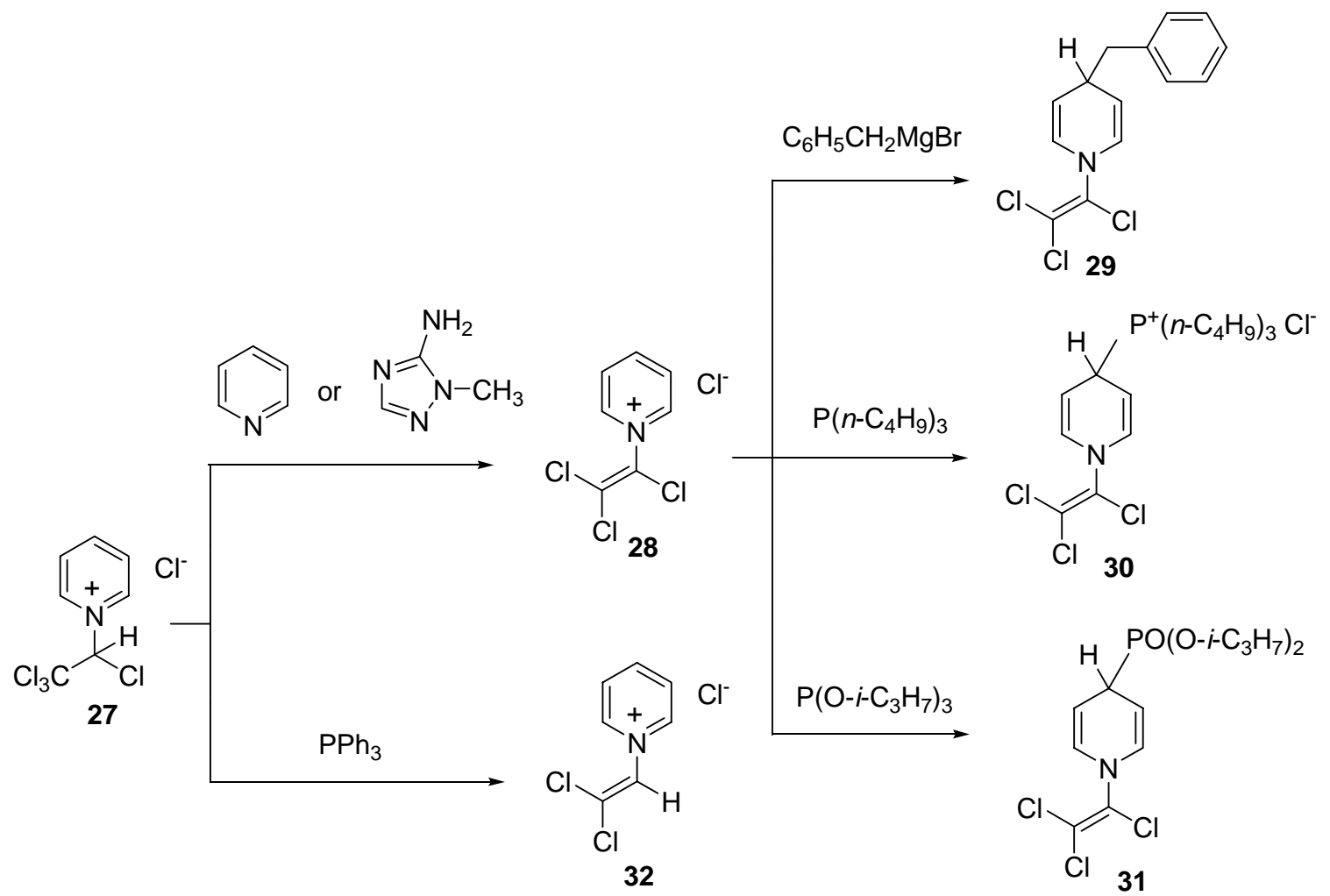

\section{Scheme 7}

\subsection{Substitution of the halogen atom and the heterocyclic moiety}

$\mathrm{N}$-(1-Haloalkyl)heteroarylium halides can also be considered as activated forms of the starting aldehydes when they undergo two consecutive substitutions of the halogen atom and the heteroarylium moiety. They have been used that way, often without prior isolation, to access, as illustrated in Scheme 8, imines, ${ }^{6 a, 6 b, 10}$ 1,1,-diamines, ${ }^{6 b}$ and a large variety of nitrogen heterocycles including dihydrobenzodiazepines (33), ${ }^{11}$ imidazolidines (34), ${ }^{10 a}$ tetrahydroquinazolines (35), ${ }^{12}$ dihydroperimidines (36), ${ }^{13}$ and thiazolidines (37). ${ }^{14}$ 1,4Dihydropyridines (38), which are well known for their antihypertensive ${ }^{15}$ effects, could also be prepared by a multicomponent reaction from $N$-(1-chloroalkyl)pyridinium chlorides (23 where X = Cl) and alkyl 3-aminobutenoates. ${ }^{16}$ When N-substituted alkyl 3-aminobutenoates were used, 
the corresponding 1-substituted 1,4-dihydropyridines were obtained. ${ }^{16 b}$ Other conventional methods generally fail to afford such derivatives.

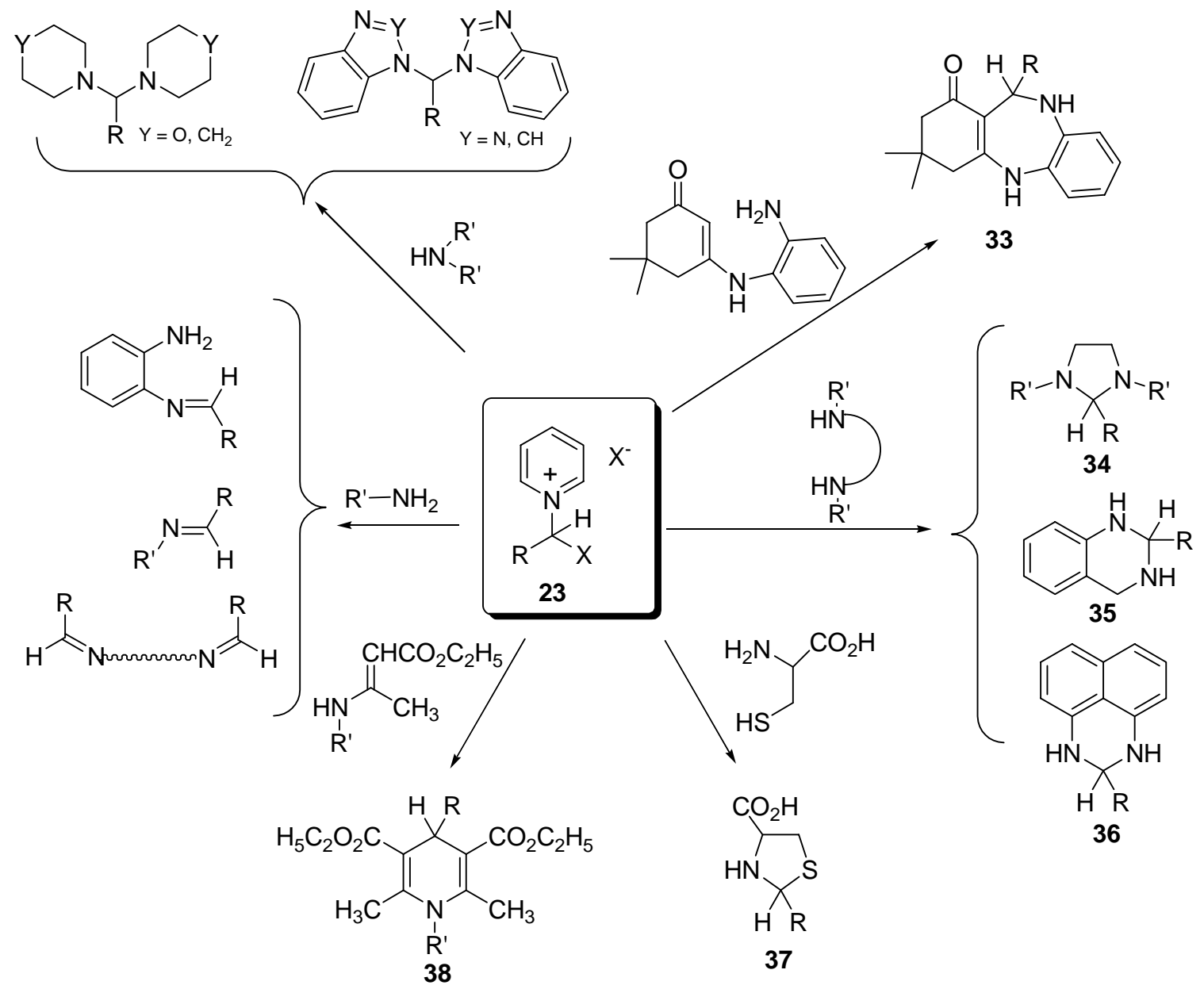

\section{Scheme 8}

Another interesting application deals with the ready synthesis ${ }^{17}$ of 2-aryl-1-arylimino-2,3dihydro- $1 H$-isoindoles (40) in high yields (90-95 \%) from primary arylamines and the bispyridinium salt 39 obtained from 1,2-phthalic dicarboxaldehyde (Scheme 9). 


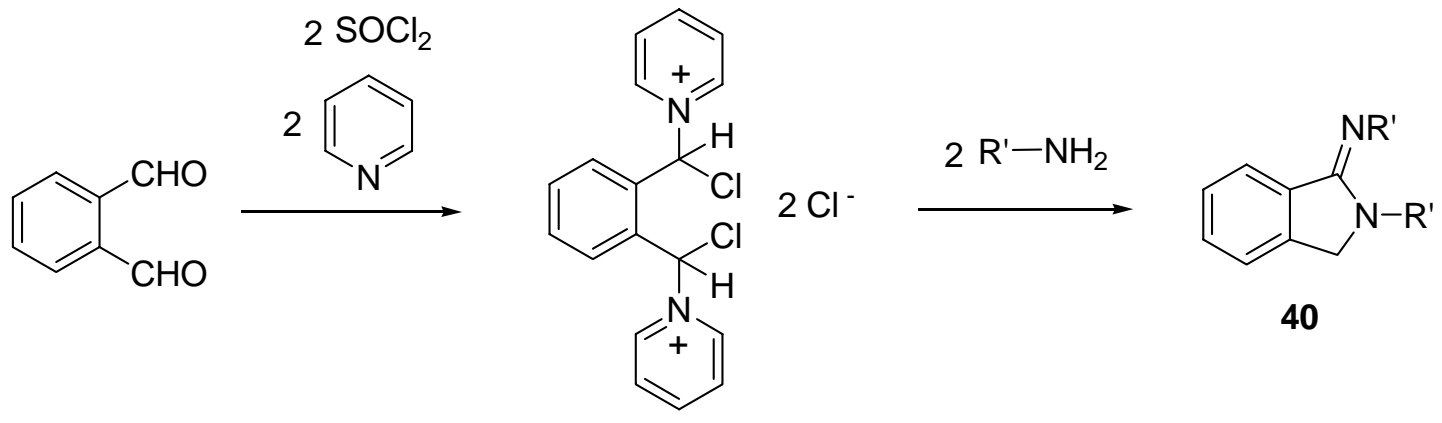

39

\section{Scheme 9}

Unexpected results (Scheme 10) were observed when $N$-(1-haloalkyl)pyridinium halides (23) were allowed to react with 1,2-phenylenediamine, 2,3-diaminopyridine, and 3,4diaminopyridine. ${ }^{10 \mathrm{~b}}$ Indeed, when the salts were not isolated, the intermediate (expected) imines or ring tautomers could not be detected because a subsequent reaction occurred yielding the corresponding oxidized compounds, namely $1 H$-benzimidazoles (41), $1 H$-imidazo[2,3b]pyridines (42), and $1 H$-imidazo[2,3-c]pyridines (43). In a similar way, $1 H$-perimidines (44) were obtained from 23 and 1,8-naphthalenediamine. ${ }^{13}$

The details of the oxidation step remain unclear but it could be linked to charge transfer complexes between sulfur dioxide and transient amino species. ${ }^{18}$ The method has been successfully applied by Huang et al. ${ }^{19}$ for the preparation of a bisbenzimidazole (45, Scheme 10) exhibiting in vitro antileishmanial activity at a submicromolar concentration.

In order to evaluate the synthetic potential of the polymer-bound fused $\mathrm{N}$-(1chloroalkyl)azinium halides $\mathbf{8}$ and $\mathbf{9}$ towards nucleophiles, they were reacted with $N, N$ '-dimethyl ethane-1,2-diamine in dichloromethane at room temperature. The experiments ${ }^{7}$ afforded the expected 2-substituted 1,3-dimethylimidazolidines 46 in good to excellent yields (50-80 \%, not optimized). After washing with an aqueous solution of sodium hydroxide, the starting neutral heterocycle-containing resin (identified by IR) was recovered and it could be recycled several times without a significant loss of activity. The sequence is illustrated in Scheme 11 in the case of the quinoline auxiliary $\mathbf{8}$. 

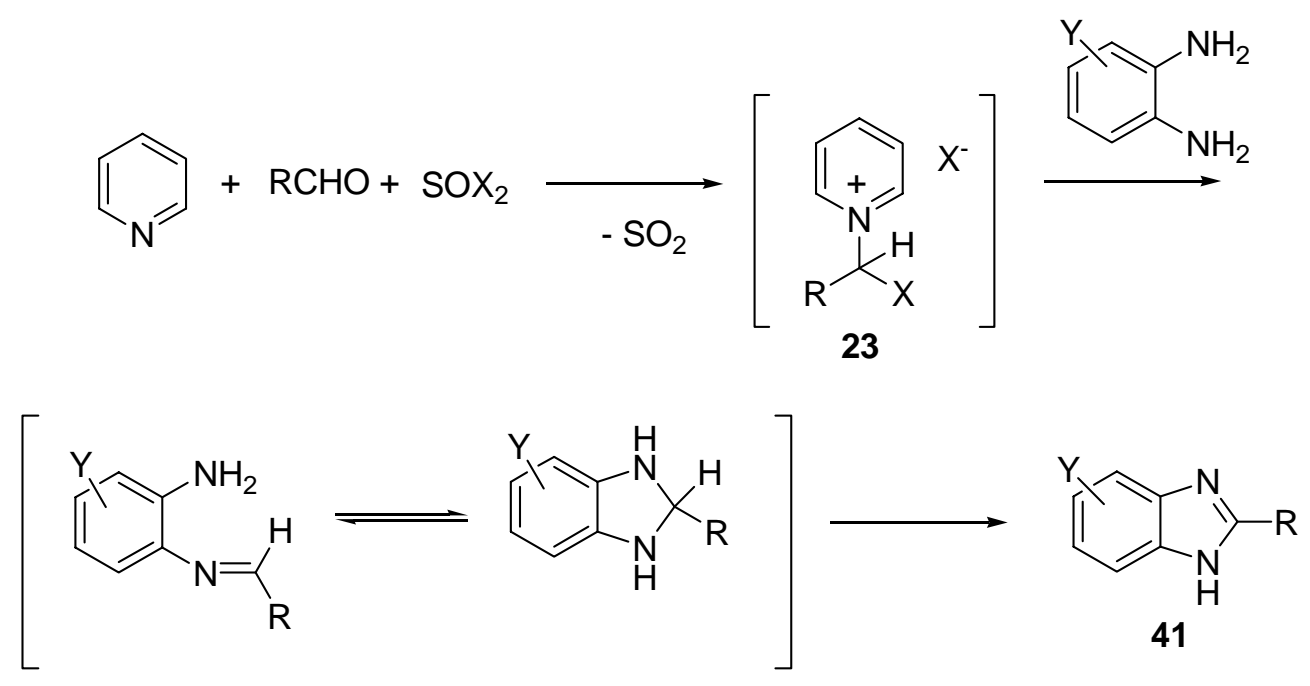<smiles>[R]c1nc2cccnc2[nH]1</smiles>

42<smiles>[R]c1nc2ccncc2[nH]1</smiles>

43<smiles>[R]C1=Nc2cccc3cccc(c23)N1</smiles>

44<smiles>c1ccc2[nH]c(-c3ccc(N4CCN(c5ccc(-c6nc7ccccc7[nH]6)cc5)CC4)cc3)nc2c1</smiles>

45

\section{Scheme 10}

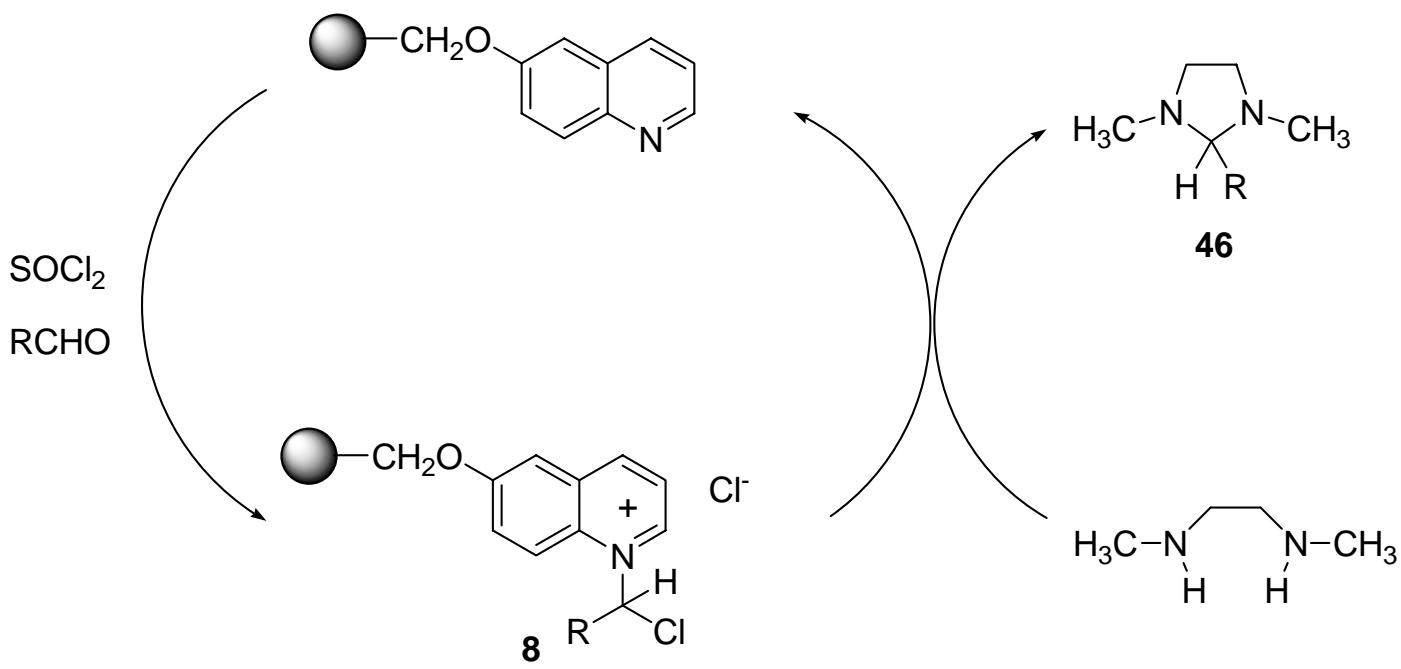

\section{Scheme 11}




\subsection{Recent developments: preparation and reactivity of bis(1,3,4-thidiazolo)-1,3,5- triazinium halides}

In recent years, Professor Anders' group has focused its attention on the reaction between $N$-(1haloalkyl)pyridinium halides (23) and two equivalents of 2-amino-5-methyl-1,3,4-thiadiazole. This is because those reactions yield ${ }^{20}$ bis(1,3,4-thiadiazolo)-1,3,5-triazinium halides (47, Scheme 12), a novel tricyclic system characterized by diverse and exciting synthetic potential. Let us mention that the parent compound (47 where $\mathrm{R}=\mathrm{H}$ ) cannot be prepared from the corresponding $N$-(1-halomethyl)pyridinium halides. ${ }^{6 \mathrm{~d}}$

Thus, 47 were obtained in excellent yields (80 \%) from 23 (or geminal bis(pyridinium) salts 48) and the aminothiadiazole in acetonitrile at $75{ }^{\circ} \mathrm{C}$ after heating for 12 hours. The structure of those tricyclic systems was ascertained by NMR spectroscopy, mass spectrometry, elemental analyses, and X-ray analyses. In particular in the ${ }^{1} \mathrm{H}$ NMR spectra of $\mathbf{4 7}$ the HC(9) signals show an upfield shift of 1-2 ppm as compared with the HC(1) signals in the starting 23 . The symmetrical structure of $\mathbf{4 7}$ is also supported by the number of signals observed in the ${ }^{13} \mathrm{C} \mathrm{NMR}$ spectra. Benzofused analogs (49) of $\mathbf{4 7}$ have been isolated ${ }^{21}$ from the reaction of 23 and 2aminobenzothiazoles.

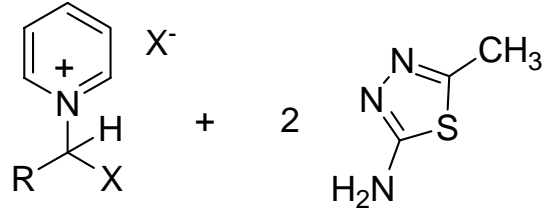

23

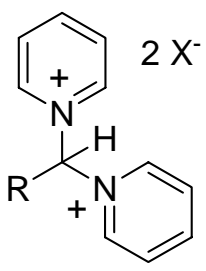

48

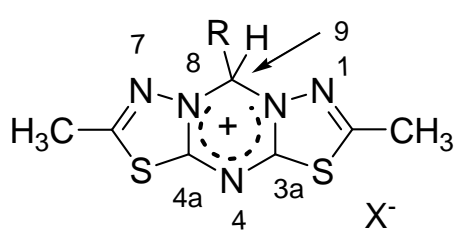

47

\section{Scheme 12}

Formation of 47 (49) reasonably proceeds ${ }^{20}$ via a multistep cascade sequence (Scheme 13) starting with two consecutive substitutions of the halogen atom and the pyridine moiety of 23. The intermediate 50 (Scheme 15) could then undergo a proton shift followed by a cyclization to give 51 and finally extrusion of ammonia afforded $\mathbf{4 7}$ and ammonium chloride or bromide, as experimentally detected. 


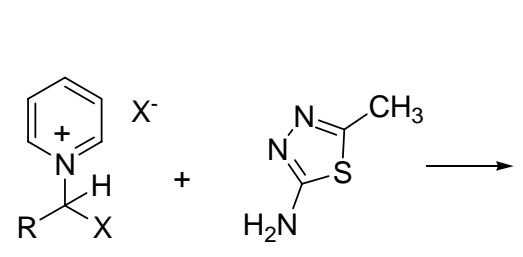

23

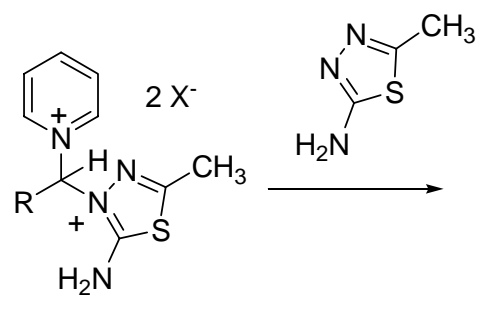

26

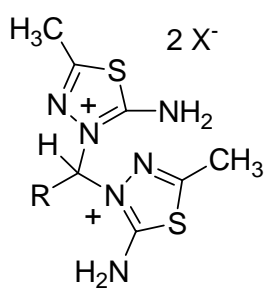

50

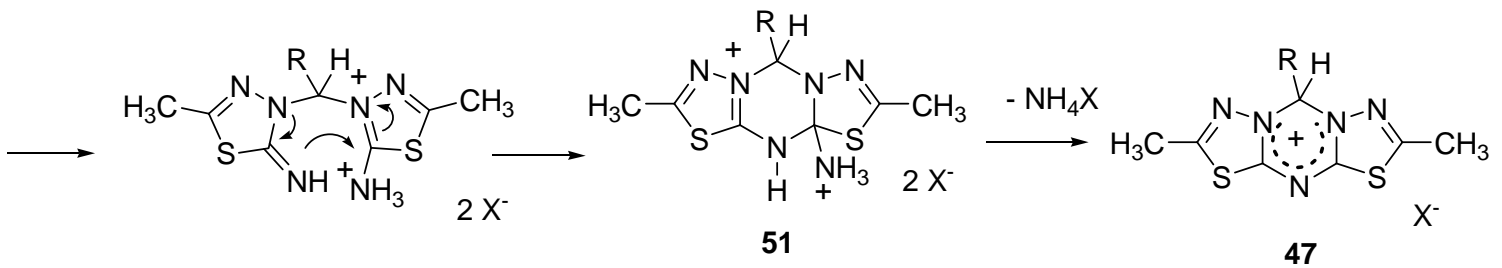

\section{Scheme 13}

Interestingly bis(1,3,4-thiadiazolo)-1,3,5-triazinium halides (47) appeared to be highly sensitive to nitrogen nucleophiles. When they were treated with primary or secondary aliphatic amines, guanidines like those represented in Scheme 14 could be isolated in good yields. ${ }^{21,} 22$ This procedure therefore represents an original route to access novel heterocycles-containing highly substituted guanidines. Some of the compounds described in Scheme 14 have been used as tailor-made ligands for complexation of $\mathrm{Cu}(\mathrm{II})$ and $\mathrm{Zn}(\mathrm{II}){ }^{23}$

The mechanism suggested ${ }^{21,}{ }^{24}$ to explain the transformation of $\mathbf{4 7}$ into guanidines (52) is depicted in Scheme 15. It is a cascade reaction in which the most important steps are (i) the deprotonation of intermediate $\mathbf{5 3}$ by the amine or an added base to give $\mathbf{5 5}$ and (ii) the cleavage of both the $\mathrm{S}(5)-\mathrm{C}(4 \mathrm{a})$ bond in the thiadiazole and then the $\mathrm{C}(9)-\mathrm{N}(10)$ bond in the triazinium ring. This rearrangement gives rise to a novel chiral center at the 2,3-dihydrothiadiazole ring in 52. Mention should be made that in species $\mathbf{5 5}$ the $\mathrm{S}(5)-\mathrm{C}(4 \mathrm{a})$ is an unusually long bond (193.6 $\mathrm{pm}^{24}$ ) due to a negative hyperconjugation effect. ${ }^{25}$ The fission of this bond needs only 7.9 $\mathrm{kcal} / \mathrm{mol}$ and gives the zwitterionic compound 56, the key intermediate determining the consecutive steps. Several zwitterions of structure $\mathbf{5 6}$ have been successfully prepared, isolated, and characterized. ${ }^{24}$ When heated above their melting point, they reacted intramolecularly and were completely transformed into the corresponding guanidines $\mathbf{5 2}$. 


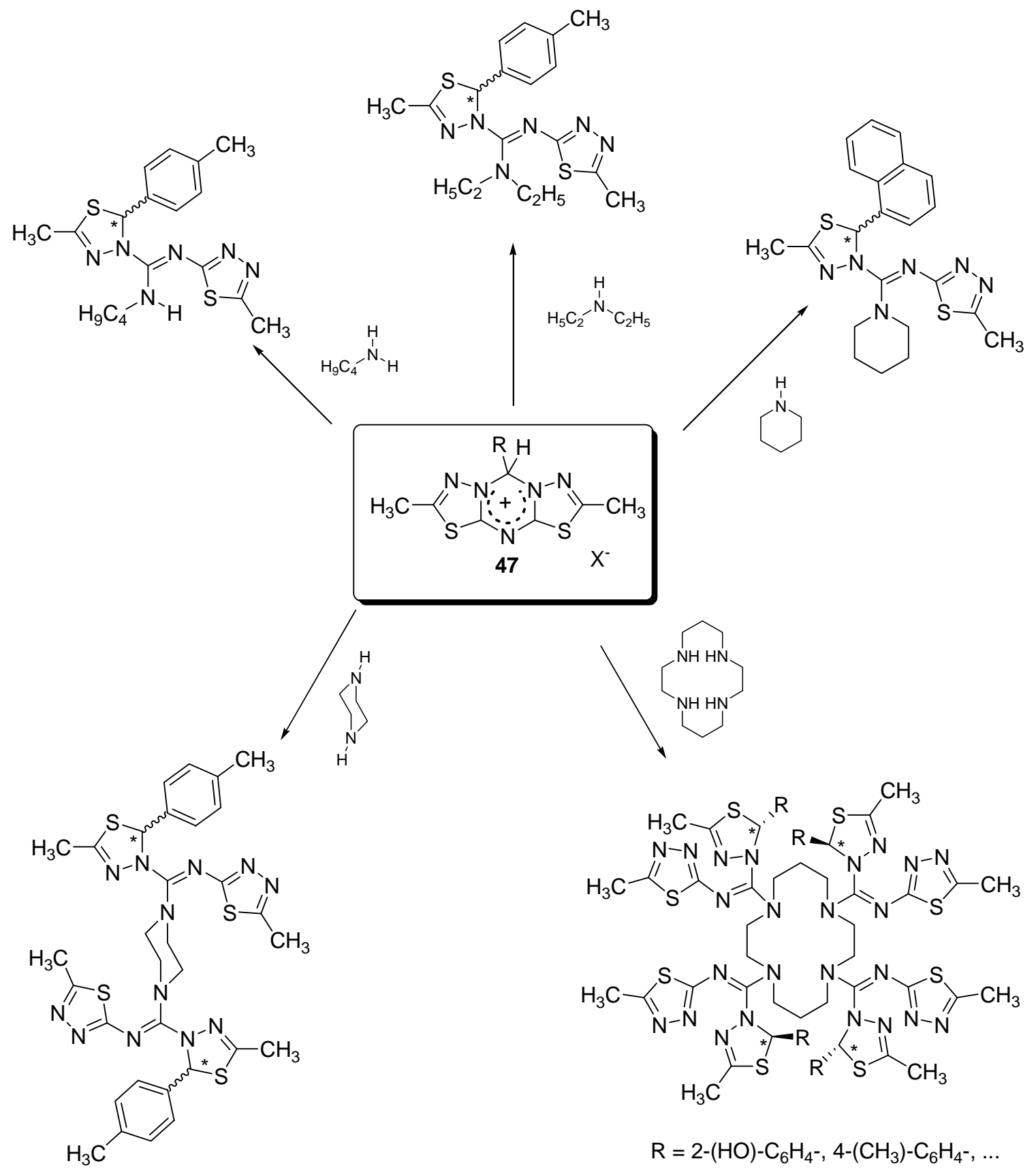

\section{Scheme 14}




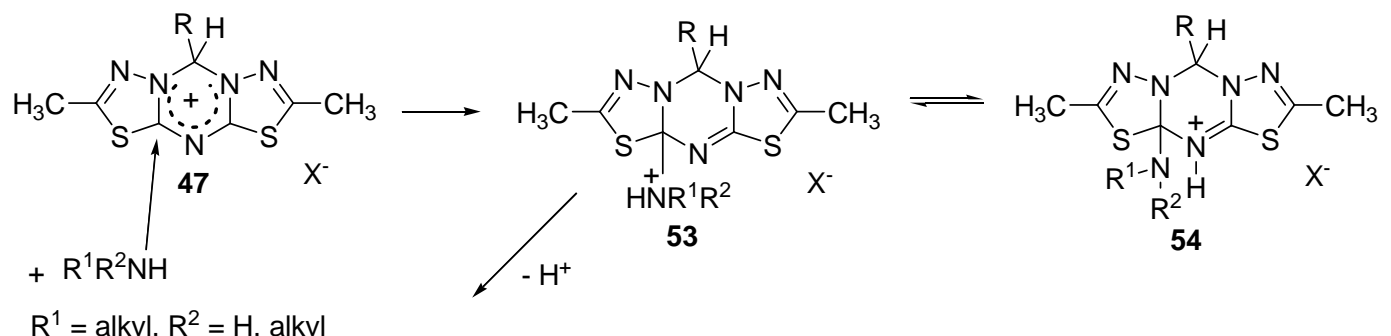

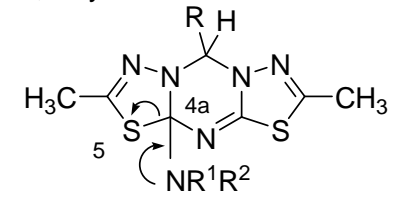

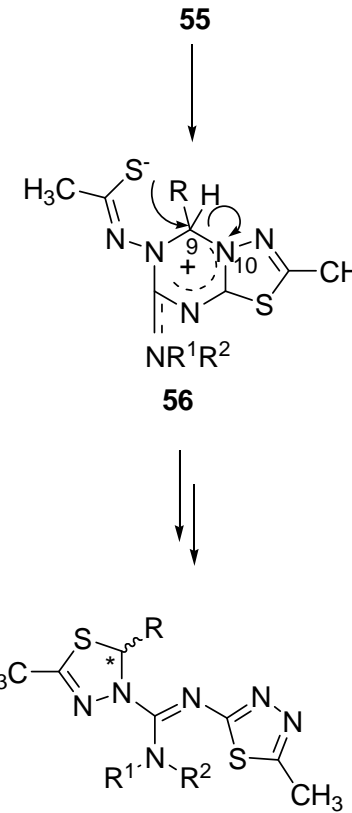
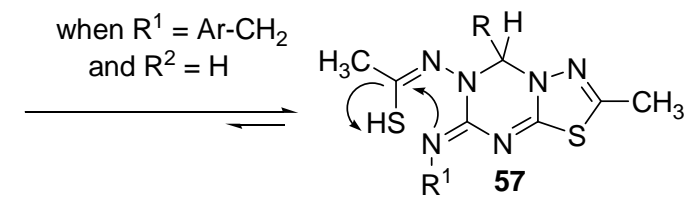

52

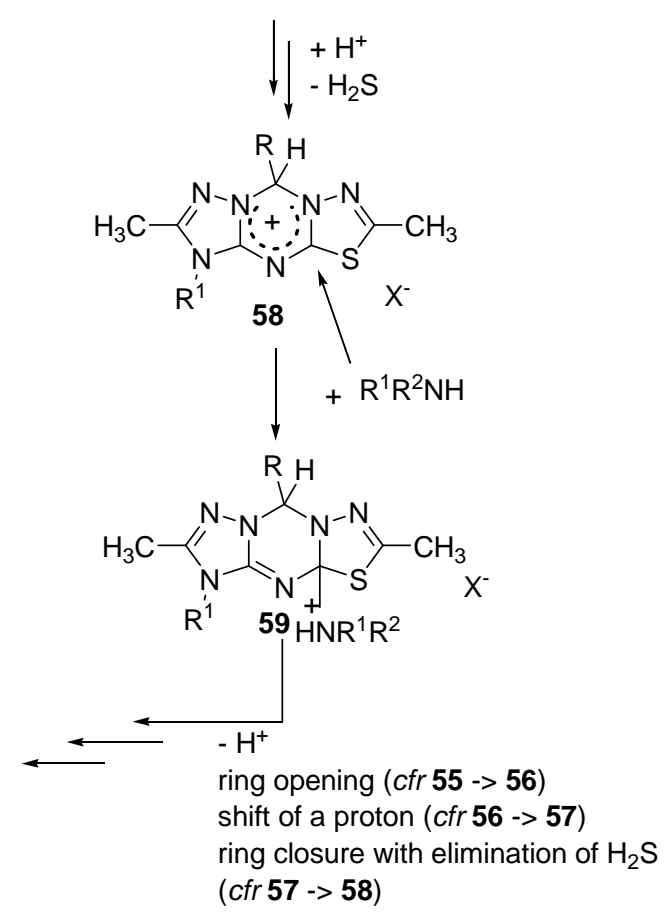

\section{Scheme 15}

Reactions with benzylamines or (aminomethyl)pyridines deserve particular attention because they gave rise to mixtures of guanidines 52 and novel fused 1,3,5-triazinium derivatives $\mathbf{6 0} .{ }^{24}$ The relative proportions of the two products were only slightly dependent on the reaction conditions. The mechanism proposed in Scheme 15 enables to account for the competition 
processes. It is based on a detailed theoretical study and supported by experimental evidences. Intermediate 56 can undergo a proton shift to afford 57, and an intramolecular reaction with extrusion of the $\mathrm{HS}^{-}$anion to yield 58, intermediates that could be isolated under particular experimental conditions and emerge as promising novel synthetic auxiliaries. ${ }^{26}$ Attack of $\mathbf{5 8}$ by benzylamine or (aminomethyl)pyridines could again follow a similar reaction pathway, finally yielding bis(1,2,4-triazolo)-1,3,5-triazinium halides 60. Because the central dihydro-1,3,5triazinium ring survives in that sequence, the reaction has been classified as a novel example of a $\mathrm{S}_{\mathrm{N}}\left(\right.$ ANRORC) mechanism. ${ }^{27}$

When less nucleophilic amines were involved, a completely different pathway occurred. Indeed, bis(thiadiazolo)triazinium halides 47 reacted with 2-amino-5-methyl-1,3,4,-thiadiazole in pyridine (15 hours at $80{ }^{\circ} \mathrm{C}$ ) to give the bis (azolyl)alkane $\mathbf{6 2}$ (Scheme 16) but in moderate yield. ${ }^{20}$ That can be interpreted by considering the cleavage of bond $\mathrm{C}(4 \mathrm{a})-\mathrm{N}(4)$ in the intermediate 54 followed by a second attack of the nitrogen nucleophile on the semi-cyclic imino bond in $\mathbf{6 1}$.
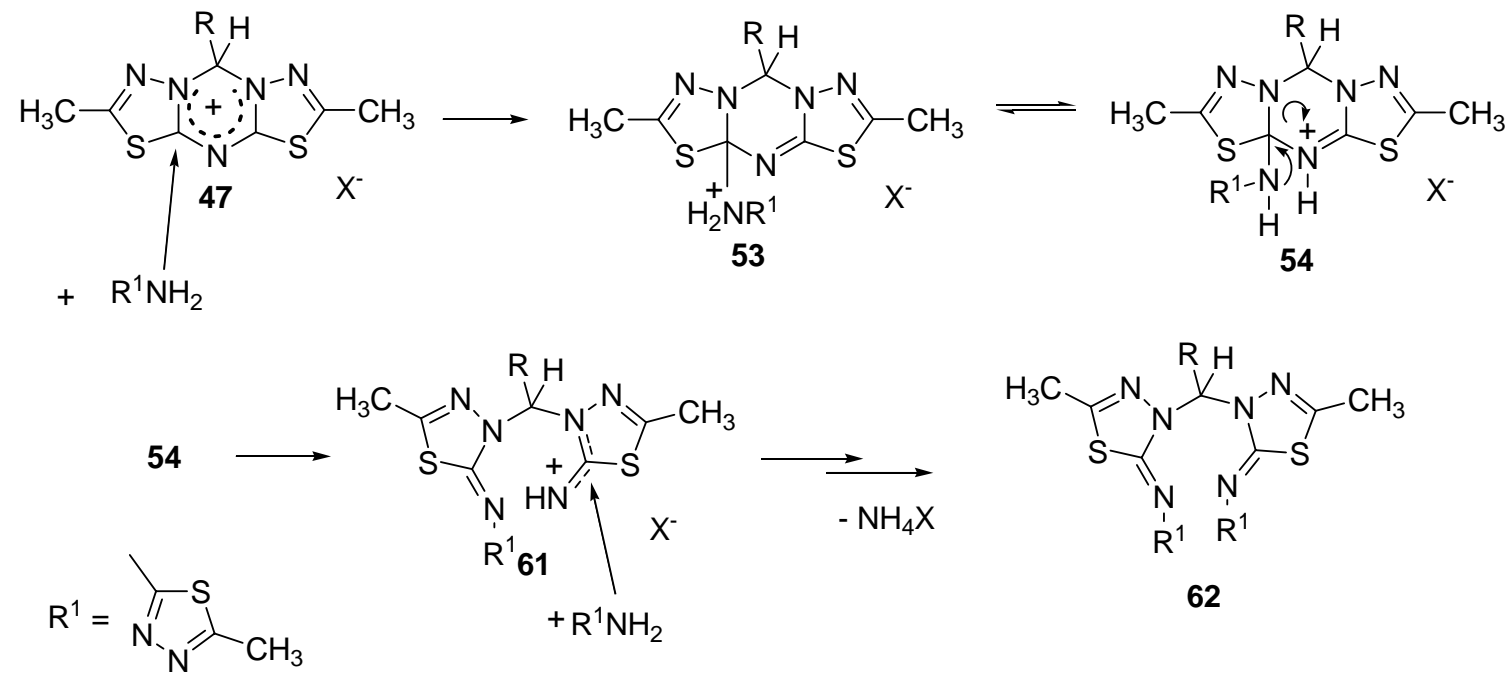

62

\section{Scheme 16}

$1 H$-1,2,4-Triazole, ${ }^{28}$ imidazole, ${ }^{28} 1$-methylimidazole, ${ }^{28}$ benzimidazole, ${ }^{28}$ as well as primary aromatic amines ${ }^{29}$ also gave rise to complex competitive mechanisms so that mixtures of compounds (including derivatives arising from hydrolysis by atmospheric water) were obtained. However formation of guanidines $\mathbf{5 2}$ could be favored by increasing the basicity of the media by addition of an external base (triethylamine). ${ }^{29}$

\section{Conclusions}

$N$-(1-Haloalkyl)heteroarylium halides represent a class of substances that had attracted little attention before the work of Ernst Anders and his group. They now emerge as potent synthetic 
auxiliaries for the preparation of diverse neutral or charged compounds that are readily available in high yields through simple experimental procedures. Their impact in organic synthesis has now found a novel niche because they are starting materials for the preparation of bis $(1,3,4$ thiazolo)-1,3,5-triazinum halides, from which various highly substituted guanidines, aminals, and triazinium halides can be accessed.

\section{References}

1. Anders, E.; Wermann, K.; Vanden Eynde, J.J. In Advances in Heterocyclic Chemistry: Chemistry of N-(1-haloalkyl)heteroarylium Salts; Katritzky A. R., Ed.; Academic: New York, 2000; Vol. 77, pp183-219.

2. (a) Kroehnke, F. Ber. 1933, 66, 1386. (b) Kroehnke, F; Boerner, E. Ber. 1936, 69, 2006. (c) Kroehnke, F.; Heffe, W. Ber. 1937, 70, 864.

3. (a) Calderon, C.H.; Shi, Y.-F.; Lampidis, T. J.; Pressman, B. C. Cell. Pharmacol. 1994, 1, 181. (b) Crociani, B.; Di Bianca, F.; Giovenco, A.; Berton, A.; Bertani, R. J. Organomet. Chem. 1989, 361, 255. (c) Crociani, B.; Di Bianca, F.; Benetollo, F ; Bombieri, G. J. Chem. Res.(S) 1992, 296. (d) Crociani, B.; Di Bianca, F.; Fontana, A.; Bertani, R. J. Organomet. Chem. 1992, 425, 155.

4. Kolomeitsev, A.; Schoth, R. M.; Lork, E.; Roeschenthaler, G. V. Chem. Commun. 1996, 335.

5. Anders, E.; Tropsch, J. G. Bull. Soc. Chim. Belg. 1987, 96, 719.

6. (a) Maquestiau, A. ; Anders, E.; Vanden Eynde, J. J.; D’Orazio, P.; Mayence, A. Bull. Soc. Chim. Belg. 1989, 98, 523. (b) Anders, E.; Tropsch, J. G.; Katritzky, A. R.; Rasala, D.; Vanden Eynde, J. J. J. Org. Chem. 1989, 54, 4808. (c) Maquestiau, A.; Anders, E.; Mayence, A.; Vanden Eynde, J. J. Chem. Ber. 1991, 124, 2013. (d) Anders, E.; Opitz, A.; Wermann, K.; Wiedel, B.; Walther, M.; Imhof, W;. Goerls, H. J. Org. Chem. 1999, 64, 3113.

7. Vanden Eynde, J. J.; Mayence, A.; Anders, E. The 14th European Symposium on Organic Chemistry, Helsinki, Finland, July 4-8, 2005; Abstract P304.

8. Anders, E.; Duray, S.; Fuchs, R.; Maas, G.; Mayence, A.; Vanden Eynde, J. J. Bull. Soc. Chim. Belg. 1997, 106, 383.

9. Anders, E.; Wermann, K.; Wiedel, B.; Vanden Eynde, J. J. Liebigs Ann./Recueil 1997, 745.

10. (a) Vanden Eynde, J. J.; Mayence, A.; Maquestiau, A.; Anders, E. Bull. Soc. Chim. Belg. 1992, 101, 233. (b) Vanden Eynde, J. J.; Mayence, A.; Maquestiau, A.; Anders, E. Bull. Soc. Chim. Belg. 1993, 102, 357.

11. Vanden Eynde, J. J.; Mayence, A.; Maquestiau, A.; Anders, E. Bull. Soc. Chim. Belg. 1992, 101, 801.

12. Vanden Eynde, J. J.; Godin, J.; Mayence, A.; Maquestiau, A.; Anders, E. Synthesis 1993, 867. 
13. Vanden Eynde, J. J.; Mayence, A.; Maquestiau, A.; Anders, E. Synth. Commun. 1992, 22, 3141.

14. Anders, E.; Duray, S. ; Fuchs, R. ; Maas, G.; Mayence, A.; Vanden Eynde, J. J. Bull. Soc. Chim. Belg. 1997, 106, 383.

15. Bossert, F.; Meyer, H.; Wehinger, E. Angew. Chem. Int. Ed. 1981, 20, 762.

16. (a) Vanden Eynde, J. J.; D’Orazio, P.; Mayence, A.; Maquestiau, A.; Anders, E. Tetrahedron 1992, 48, 1263. (b) Vanden Eynde, J. J.; Mayence, A.; Maquestiau, A.; Anders, E. Synth. Commun. 1992, 22, 3291. (c) Vanden Eynde, J. J.; Anders, E.; Maquestiau, A.; Mayence, A. Chem. Ber. 1993, 126, 1251.

17. Vanden Eynde, J. J.; Mayence, A.; Maquestiau, A.; Anders, E. Bull. Soc. Chim. Belg. 1992, 101, 509.

18. (a) Baterman, L. C.; Hughes, E. D.; Ingold, C. K. J. Chem. Soc. 1944, 243. (b) Bonnaterre, R.; Cauquis, G. Bull. Soc. Chim. Fr. 1972, 3297. (c) Ben Alloum, A.; Bougrin, K.; Soufiaoui, M. Tetrahedron Lett. 2003, 44, 5935.

19. Mayence, A.; Vanden Eynde, J. J.; LeCour Jr. L.; Walker, L. A. ; Tekwani, B. L.; Huang, T. L. Eur. J. Med. Chem. 2004, 39, 547.

20. Anders, E.; Wermann, K.; Wiedel, B.; Guenther, W.; Goerls, H. Eur. J. Org. Chem. 1998, 2923.

21. Wermann, K.; Walther, M.; Guenther, W.; Goerls, H.; Anders, E. J. Org. Chem. 2001, 66, 720.

22. Walther, M.; Wermann, K.; Goerls, H.; Anders, E. Synthesis 2001, 1327.

23. Walther, M.; Wermann, K.; Lutsche, M.; Guenther, W.; Goerls, H.; Anders, E. J. Org. Chem. 2006, 71, 1399.

24. 24.Wermann, K.; Walther, M.; Guenther, W.; Goerls, H.; Anders, E. Eur. J. Org. Chem. 2003, 1389.

25. (a) Anders, E.; Merkus, F.; Meske, H.; Tropsch, J.; Maas, G. Chem. Ber. 1987, 120, 735. (b) Anders, E.; Hertlein, K.; Meske, H. Synthesis 1990, 323. (c) Nordhoff, K.; Anders, E. J. Org. Chem. 1999, 64, 7485. (d) Nilson Lill, S. O.; Rauhut, G.; Anders, E. Chem. Eur. J. 2003, 9, 3143.

26. Wermann, K.: Walther, M.; Guenther, W.; Goerls, H.; Anders, E. Tetrahedron 2005, 61, 673.

27. van der Plas, H. C. In Advances in Heterocyclic Chemistry; Katritzky, A. R., Ed.; Academic: New York, 1999; Vol. 74, pp 1-253.

28. Wermann, K.; Walther, M.; Anders, E. Arkivoc 2002, (x), 24.

29. Wermann, K.; Walther, M.; Goerls, H. Anders, E. Synlett 2003, 1459. 